\title{
Circadian adaptations to meal timing: neuroendocrine mechanisms
}

\section{Danica F. Patton and Ralph E. Mistlberger*}

Department of Psychology, Simon Fraser University, Burnaby, BC, Canada

\section{Edited by:}

Alfonso Abizaid, Carleton University,

Canada

Reviewed by:

Tatsushi Onaka, Jichi Medical

University, Japan

Elliott Albers, Georgia State

University, Georgia

*Correspondence:

Ralph E. Mistlberger, Department of Psychology, Simon Fraser University, 8888 University Drive, Burnaby BC

V5A 1S6, Canada

e-mail:mistlber@sfu.ca
Circadian rhythms of behavior and physiology are generated by central and peripheral circadian oscillators entrained by periodic environmental or physiological stimuli. A master circadian pacemaker in the hypothalamic suprachiasmatic nucleus (SCN) is directly entrained by daily light-dark (LD) cycles, and coordinates the timing of other oscillators by direct and indirect neural, hormonal and behavioral outputs. The daily rhythm of food intake provides stimuli that entrain most peripheral and central oscillators, some of which can drive a daily rhythm of food anticipatory activity if food is restricted to one daily mealtime. The location of food-entrainable oscillators (FEOs) that drive food anticipatory rhythms, and the food-related stimuli that entrain these oscillators, remain to be clarified. Here, we critically examine the role of peripheral metabolic hormones as potential internal entrainment stimuli or outputs for FEOs controlling food anticipatory rhythms in rats and mice. Hormones for which data are available include corticosterone, ghrelin, leptin, insulin, glucagon, and glucagon-like peptide 1. All of these hormones exhibit daily rhythms of synthesis and secretion that are synchronized by meal timing. There is some evidence that ghrelin and leptin modulate the expression of food anticipatory rhythms, but none of the hormones examined so far are necessary for entrainment. Ghrelin and leptin likely modulate food-entrained rhythms by actions in hypothalamic circuits utilizing melanocortin and orexin signaling, although again food-entrained behavioral rhythms can persist in lesion and gene knockout models in which these systems are disabled. Actions of these hormones on circadian oscillators in central reward circuits remain to be evaluated. Food-entrained activity rhythms are likely mediated by a distributed system of circadian oscillators sensitive to multiple feeding related inputs. Metabolic hormones appear to play a modulatory role within this system.

Keywords: circadian, food entrainment, ghrelin, leptin, melanocortin, corticosterone, orexin, insulin

\section{INTRODUCTION}

Behavior and physiology are regulated by a hierarchically organized system of circadian oscillators located in the brain and in most peripheral tissues and organs (Figure 1). Circadian timekeeping coordinates cellular and physiological processes internally, and synchronizes these with daily cycles in the environment, ensuring that biological activities, from gene expression to foraging behavior, occur in the right sequence and at the right time of day. Although daily light-dark (LD) cycles are considered to be the dominant environmental stimulus for synchronizing circadian oscillators to local time, for many circadian processes, it is the timing of food intake that is most important. In this review, we briefly outline the evidence that feeding patterns regulate circadian clocks in mammals. We then critically examine the role of metabolic and stress-related hormones in this process. An important objective for the purposes of this Frontiers Topic (neuroendocrine mechanisms that connect feeding behavior and stress) is to draw attention to chronobiological concepts that provide a framework for understanding how anything that can affect feeding behavior, including acute or chronic stress stimuli (Maniam and Morris, 2012; Patterson and Abizaid, 2013; Sinha and Jastreboff, 2013), can potentially alter circadian organization within the brain and in peripheral organs and tissues. Whether the consequences for the organism are adaptive or pathological may depend on the temporal parameters of feeding behavior.

\section{MEAL TIMING ENTRAINS CIRCADIAN CLOCKS}

The role of food intake in the regulation of circadian clocks was first revealed by studies of circadian activity rhythms in food-restricted rodents. Acute and chronic food restriction elicit well-known behavioral and physiological responses to maintain metabolic homeostasis. Acute deprivation recruits neural circuits that promote arousal and food seeking behavior. Chronic caloric restriction induces physiological adaptations to facilitate the extraction and storage of energy from ingested nutrients and to reduce energy expenditure. If caloric restriction is chronic and food availability is limited to a particular time of day, further adaptations can occur in the temporal regulation of metabolism and food seeking behavior. These adaptations involve entrainment of circadian clocks in the brain and in peripheral organs and tissues by stimuli associated with food intake.

Physiology and behavior are regulated by circadian clocks that induce daily rhythms in synchrony with environmental cycles. In mammals, a master circadian clock is located in the 


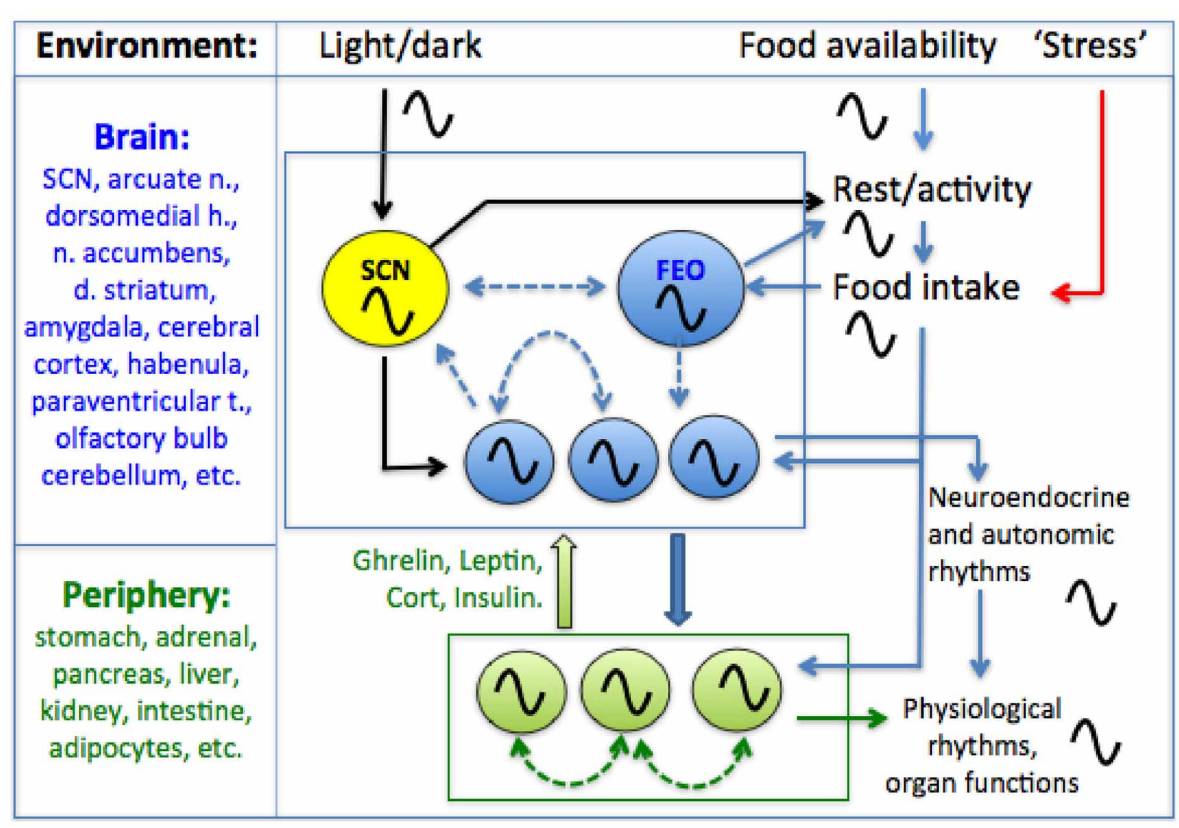

FIGURE 1 | A conceptual model of the mammalian circadian system. A circadian pacemaker located in the retinorecipient suprachiasmatic nucleus (SCN) in the hypothalamus generates circadian rest-activity, feeding, body temperature and other rhythms that entrain to environmental light-dark (LD) cycles. The daily feeding rhythm provides time cues that entrain circadian oscillators elsewhere in the brain and in most peripheral organs and tissues. Limiting food access to a single daily meal entrains central and peripheral oscillators, decoupling these from the SCN pacemaker which remains entrained to LD. Some SCN-independent food-entrainable oscillators (FEOs) drive daily rhythms of food anticipatory activity. The location of these FEOs and the signals that entrain them to mealtime, remain to be determined. Peripheral clocks could entrain central FEOs via hormonal pathways involving ghrelin, leptin, corticosterone and insulin, although none of these alone are required for food-anticipatory activity rhythms. Solid arrows indicated interactions for which empirical evidence exists, while dashed arrows indicate possible interactions (coupling among oscillators in different structures). For simplicity, some other possible interactions among and between central and peripheral clocks and meal-related cues are omitted. suprachiasmatic nucleus (SCN) of the anterior hypothalamus (Weaver, 1998; Welsh et al., 2010). The SCN contains a large population of circadian oscillator cells that are entrained to daily LD cycles via a direct input from intrinsically photoreceptive retinal ganglion cells. SCN ablation eliminates circadian organization of behavior and physiology if food is freely available. Circadian oscillators also exist in other brain regions and most if not all peripheral organs and tissues (Yamazaki et al., 2000; Guilding and Piggins, 2007; Dibner et al., 2010). Within each tissue, circadian oscillator cells must be coupled with each other for circadian organization to emerge at the tissue level. The SCN plays a special role within this multioscillatory system by providing signals that maintain coupling of oscillators within most tissues. SCN timing signals are conveyed by neural (autonomic), hormonal (hypothalamo-pituitary) and behavioral pathways (Dibner et al., 2010). Of particular importance is SCN control of the daily rhythm of feeding behavior. A dominant role for food intake in the control of peripheral rhythms is readily demonstrated by restricting rats and mice to a $2-6 \mathrm{~h}$ mealtime in their usual rest phase (the lights-on period), when they normally eat very little. Scheduled daytime feeding shifts the timing of clock gene rhythms and functional rhythms in most peripheral organs and tissues to realign with expected mealtime (Boulos and Terman, 1980; Dibner et al., 2010). If a daily LD cycle is present, the SCN itself is not shifted by daytime feeding schedules (Damiola et al.,
2000; Hara et al., 2001a; Stokkan et al., 2001). Dissociation of peripheral oscillators from the SCN during restricted daytime feeding suggests that the SCN normally coordinates daily rhythms of physiology by its role as the pacemaker for feeding behavior.

Restricted daytime feeding also induces a behavioral rhythm of food seeking behavior that anticipates the daily mealtime (Figure 2) (Boulos and Terman, 1980; Mistlberger, 1994; Stephan, 2002). If the SCN are ablated and food is available ad-libitum, behavior and physiology lose circadian organization. However, if food is provided once every $24 \mathrm{~h}$ in a reduced amount, food anticipatory activity rhythms emerge and circadian rhythms of physiology are restored (Stephan et al., 1979; Boulos et al., 1980). The timing of food intake is thus fundamental to circadian organization of behavior and physiology and involves effects of food on circadian oscillators downstream from the master, LD-entrained circadian pacemaker in the SCN.

Despite the significance of food as a "zeitgeber" (entrainment cue) for circadian regulation of food-anticipatory behavior, the neural and molecular mechanisms of this SCN-independent circadian function are not yet well-understood. The daily rhythm of food anticipatory activity exhibits canonical properties of circadian clock control (Boulos and Terman, 1980; Mistlberger, 1994; Stephan, 2002). Once established, the rhythm persists for several cycles during total food deprivation (Figure 2C); the timing mechanism is therefore self-sustaining, unlike simple hourglass or 

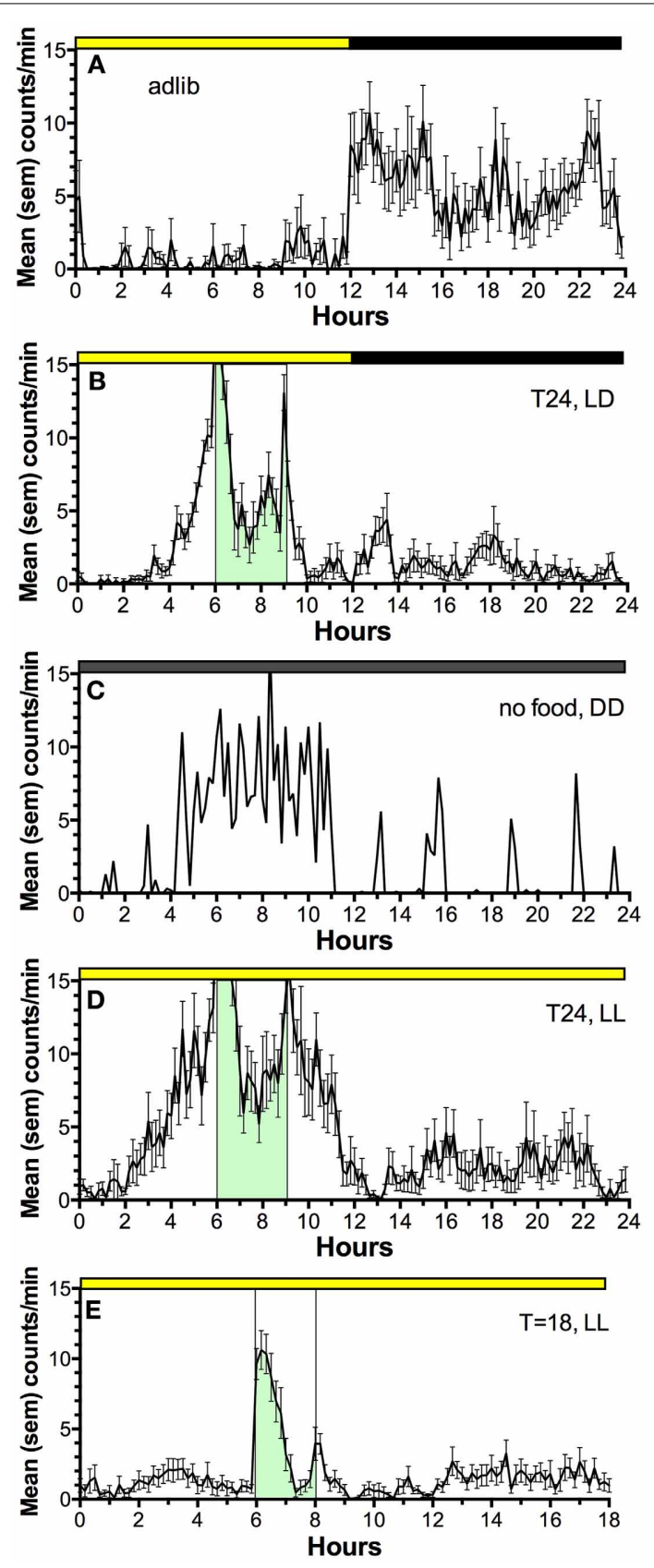

FIGURE 2 | Average waves illustrating the temporal distribution of spontaneous locomotor activity of a representative rat under the following feeding conditions. (A) ad-lib access to food (10 day average). (B) Food restricted to 3-h/day, beginning $6 \mathrm{~h}$ after lights on, for 3 weeks (last 10 day average). (C) Day 2 of total food deprivation after 3 weeks of restricted daytime feeding. (D) Food restricted to 3-h/day for 3 weeks, after a month in constant light with food ad-lib, to eliminate the light-entrainable, free-running rhythm controlled by the SCN (a reversible SCN "lesion" procedure). (E) Food restricted to 2-h/day in constant light, delivered every $18 \mathrm{~h}$, illustrating failure of rats to anticipate a daily meal at regular but non-circadian intervals. Mealtime is denoted by green shading and vertical bars. Activity was measured by motion sensors, and plotted as average counts per minute, in $10 \mathrm{~min}$ bins. interval timers (e.g., like a stomach that gradually empties after a large meal). If the feeding schedule differs greatly from $24 \mathrm{~h}$ (e.g., is $<22$ or $>30 \mathrm{~h}$ ) the food anticipation rhythm does not emerge (Figure 2E); it has so-called "limits to entrainment" that suggest involvement of an oscillator with an intrinsic periodicity in the circadian $(\sim 24 \mathrm{~h})$ range. If the mealtime is shifted by $6 \mathrm{~h}$ or more to a new time of day, the food anticipation rhythm takes several days to realign with mealtime. These properties have been interpreted as evidence that one or more correlates of food intake entrain a circadian oscillator (or population of oscillators) that determines the daily timing of foraging activity. Given that circadian food anticipatory rhythms persist in $\mathrm{SCN}$-ablated rats and mice, food-entrainable oscillators (FEOs) hypothesized to drive anticipatory behavior must be located elsewhere in the brain or body. There are many candidate sites, because, as noted, daily feeding schedules synchronize circadian oscillators in many brain regions and virtually every organ system (Feillet et al., 2006, 2008; Verwey and Amir, 2009; Dibner et al., 2010). Lesion studies have so far failed to confirm a single critical locus in the brain (Mistlberger, 1994, 2011; Davidson, 2009), suggesting that circadian timing of food anticipatory activity involves an anatomically distributed population of FEOs. It is also likely that there are multiple stimuli associated with scheduled feeding that are capable of functioning as zeitgebers for entraining FEOs.

In the following sections, we evaluate a potential role for metabolic hormones as signals by which FEOs are coupled to daily feeding schedules, or by which FEOs broadcast timing information to neural circuits that organize food seeking behavior. Although the primary emphasis is on food entrained circadian regulation of behavior, these hormonal signals may also play a role synchronizing circadian clocks and functions in peripheral organs (Dibner et al., 2010). The light-entrainable circadian pacemaker in the $\mathrm{SCN}$, as noted, remains entrained to $\mathrm{LD}$ cycles regardless of the timing of food intake. There are limited circumstances under which its phase can be controlled or modified by mealtime (e.g., in constant dark or light; Abe et al., 1989; Mistlberger, 1993; Challet, 2010), but neural and hormonal signals that mediate these effects are little studied. Consequently, the literature reviewed here concerns circadian oscillators located outside of the SCN pacemaker.

To be considered a candidate as an entrainment signal for food anticipatory circadian rhythms, a hormone (or any stimulus factor) should exhibit a daily rhythm that is induced by or is synchronous with scheduled feeding. The factor should be capable of shifting the phase of one or more food-entrained rhythms (a requirement for co-activation by 2 or more factors is possible). Blocking the factor may prevent shifting of one or more food entrained rhythms (unless there are multiple redundant signals). To be considered a candidate as an output of FEOs responsible for driving food anticipatory activity (or other food entrained rhythms) the factor should exhibit a daily rhythm that correlates strongly with locomotor activity (or other rhythms), under a variety of conditions (e.g., during total food deprivation, when food anticipatory rhythms established by scheduled feeding persist for several cycles despite the absence of a daily meal). Enhanced expression of the factor may increase the amplitude 
of food anticipatory activity (or other rhythms), while blocking the factor should attenuate or prevent expression of food anticipatory activity (or other rhythms). Attenuation could be modest or negligible if there are multiple redundant output signals. Food anticipation could also be enhanced or attenuated by factors that are downstream from FEOs, or that converge downstream via other pathways. Therefore, the observation that manipulation of a factor alters the amount of food anticipatory activity does not alone permit a strong conclusion that the factor is either an input or output of FEOs.

\section{PERIPHERAL HORMONAL MECHANISMS CORTICOSTERONE}

The synthesis and secretion of corticosterone (CORT) from the adrenal gland is under control of descending neural (autonomic) and hormonal (adrenocorticotropin) signals, interacting with circadian oscillators intrinsic to cells of the adrenal gland (Kaneko et al., 1981; Oster et al., 2006). Daily restricted feeding markedly alters the circadian profile of circulating CORT levels (Krieger, 1974). In nocturnal rodents under ad lib feeding conditions CORT levels peak close to dark onset. When food is restricted to the middle of the light phase, the daily rhythm of CORT secretion becomes bimodal, with one peak occurring at the expected mealtime and a second at the beginning of the dark period (Krieger, 1974). Treatment with sodium pentobarbital can suppress the pre-feeding peak while sparing the nocturnal peak, suggesting that these two peaks are stimulated by separate neural mechanisms (Honma et al., 1984a).

The correlated rise of CORT release and food seeking activity prior to mealtime raises the possibility that CORT may function as an endogenous entrainment signal for FEOs or as an output from FEOs to behavior. However, preprandial CORT secretion has been ruled out as a signal involved in food anticipatory behavioral rhythms, as adrenalectomized rats display apparently normal food anticipatory activity (Stephan et al., 1979; Boulos et al., 1980; Segall et al., 2008; Sujino et al., 2012). The available evidence reveals no obvious difference in the rate at which anticipation emerges or in the magnitude or duration of steady state anticipatory activity in adrenalectomized rats. This conclusion is supported by studies of food anticipation in rats provided with two daily meals separated by $6 \mathrm{~h}$ or more. Under these schedules rat readily anticipate both meals and continue to concentrate activity at both expected mealtimes during total food deprivation tests. The properties of each bout of anticipation suggest involvement of two independently entrained FEOs (Stephan, 1989; Mistlberger et al., 2012). At a $6 \mathrm{~h}$ inter-meal interval, CORT secretion rises in anticipation of the first meal, but does not rise again until near the end of the second meal (Honma et al., 1984b). When the meals were omitted only the peak to the first meal was observed, thereby dissociating CORT secretion from behavioral anticipation of the second meal.

Circadian oscillators in peripheral organs, including the adrenal gland, liver, stomach, intestines, pancreas, kidney, heart, and lungs, are entrained by daily feeding schedules (Damiola et al., 2000; Stokkan et al., 2001; Davidson et al., 2003). Circadian clock gene oscillations in many of these tissues can also be shifted by glucocorticoid administration (Balsalobre et al., 2000; Reddy et al., 2007; Pezuk et al., 2012) or by adrenalectomy (Pezuk et al., 2012), suggesting a role for glucocorticoids in phase control of peripheral clocks during adlib food access, and potentially also during restricted feeding. A strong form of the latter hypothesis, that glucocorticoids may be necessary for resetting of peripheral tissues during restricted feeding, is refuted by observations that peripheral clocks shift more rapidly in response to daytime feeding in adrenalectomized mice or knockout mice lacking hepatic glucocorticoid receptors (Balsalobre et al., 2000; LeMinh et al., 2001). This indicates that nocturnal glucocorticoid secretion normally reinforces circadian organization of peripheral clocks in rodents with adlib food access, by opposing rapid phase shifts that might be induced by transient alterations of food access. This role may be more prominent for some tissues. Circadian clock gene rhythms in the liver are not shifted by a daily CORT injection meant to simulate a mid-day feeding schedule (Stokkan et al., 2001) and shifting of the liver clock by mid-day feeding is not impeded by a late-day CORT injection meant to simulate the normal nocturnal rise of CORT. By contrast, shifting of circadian clocks in the kidney and lungs to restricted feeding is blocked by a late day CORT injection. These findings indicate that peripheral oscillators likely respond to multiple feeding-related signals in a tissue specific manner.

\section{GHRELIN}

Acyl-ghrelin and des-acyl ghrelin are peptide hormones derived from preproghrelin, which is synthesized by oxyntic cells of the stomach (Kojima et al., 1999) and by neurons in medial and lateral hypothalamic nuclei (Cowley et al., 2003). Systemic and intracerebroventricular (ICV) administration of acyl-ghrelin stimulates feeding in rats and mice (Nakazato et al., 2001; Toshinai et al., 2006). Des-acyl ghrelin may also stimulate feeding if administered (ICV), but not systemically (Toshinai et al., 2006). The orexigenic action of gastric ghrelin is mediated primarily by activation of agouti-related peptide and neuropeptide $\mathrm{Y}$ (AgRP/NPY) neurons in the arcuate nucleus (ARC), resulting in release of AgRP and NPY. Ghrelin also exerts an inhibitory action at proopiomelanocortin (POMC) neurons, preventing release of anoxerigenic peptides. The growth hormone secretagogue 1 receptor (GHSR) is the only known ghrelin receptor and is found in high levels in the ARC. GHSR mRNA has also been localized to multiple hypothalamic areas involved in feeding and arousal and extra-hypothalamic regions including the hippocampus, ventral tegmental area (VTA), substantia nigra (SN), tuberomammilary nucleus (TMN), Edinger-Westphal nucleus (EN), dorsal and median raphe nuclei, laterodorsal tegmental nuclei and the facial nucleus (Guan et al., 1997).

Plasma ghrelin increases prior to scheduled meals in food restricted rats and mice (Bodosi et al., 2004; Drazen et al., 2006; LeSauter et al., 2009) and prior to scheduled or habitual mealtimes in humans (Cummings et al., 2001; Frecka and Mattes, 2008). Gastric oxyntic cells exhibit a daily rhythm of circadian clock gene expression that is entrained by restricted feeding, suggesting that food-anticipatory release of gastric ghrelin is a function of gastric FEOs (LeSauter et al., 2009). The foodentrainable rhythmicity and orexigenic properties of gastric ghrelin present an intriguing circumstantial case that gastric ghrelin 
may participate in the regulation of circadian food anticipatory rhythms, either by stimulating appetite and activity or by entraining central clocks that drive behavioral rhythms. This hypothesis can be evaluated by the results of correlation, stimulation and gene knockout studies.

Plasma ghrelin and locomotor activity exhibit a correlated rise prior to a scheduled daily meal but become dissociated during subsequent total food deprivation tests. Food entrained activity recurs at the expected mealtime for at least 4 days without food (Boulos et al., 1980; Mistlberger, 1994). This property is critical to the interpretation that anticipation of a daily meal is based on entrainment of a self-sustaining circadian clock. Acylghrelin also rises prior to the first skipped meal, but beyond a day of fasting decreases and remains at low levels. Des-acyl ghrelin, which does not stimulate feeding or activity following systemic administration, is responsible for the rise of total plasma ghrelin evident during extended fasting (Liu et al., 2008; Kirchner et al., 2009). A similar dissociation between acyl-ghrelin and food anticipatory activity during food deprivation tests is evident in rats fed two daily meals separated by $12 \mathrm{~h}$ (Patton et al., 2012). During the first $24 \mathrm{~h}$ without food, ghrelin levels rise in anticipation of the first mealtime but then remain elevated for the rest of the day, unlike locomotor activity, which decreases after the first meal before rising prior to the second mealtime $10 \mathrm{~h}$ later (Patton et al., 2012). A third dissociation can be inferred from studies of clock gene rhythms in the stomach of rats entrained to a midday meal for several weeks, and then allowed ad-lib food access for a week. If the food is then removed for 2-4 days, the rats become active at the previous mid-day mealtime. The gastric circadian clock, by contrast, is shifted by daytime feeding, but reverts to its original phase after a few days of adlib feeding (Davidson et al., 2003). If gastric ghrelin secretion is controlled by gastric circadian oscillators, then plasma ghrelin should rise at night and not in the middle of the day when food anticipatory activity reappears during deprivation tests.

Although systemic administration of acyl-ghrelin stimulates food intake, its effect on locomotor activity is less clear. In mice, central administration of acyl-ghrelin increased eating, activity and wake time, while peripheral ghrelin stimulated food intake but did not alter either wake time or locomotor activity for 1 and $6 \mathrm{~h}$ post-injection (Szentirmai, 2012). At orexigenic doses, systemically administered ghrelin was not sufficient to stimulate activity, as predicted if gastric ghrelin were responsible for circadian food anticipatory activity.

The availability of ghrelin ligand and receptor knock-out mice permits a direct assessment of whether ghrelin is necessary for food anticipatory activity. The results of 5 studies are consistent in demonstrating that mice do not require ghrelin signaling to anticipate a daily meal (Figure 3). Three of these studies reported food anticipatory activity and body temperature in ghrelin ligand knockout mice (Szentirmai et al., 2010; Gunapala et al., 2011) (Figures 3C,D) or ghrelin receptor KO mice (Gooley et al., 2006) that did not differ from anticipatory activity in WT mice. Two other studies also reported significant FAA in ghrelin receptor $\mathrm{KO}$ mice, but with alterations relative to WT mice. In one case, the average duration of FAA was decreased (i.e., the onset was closer to mealtime) without a change in the peak level (LeSauter
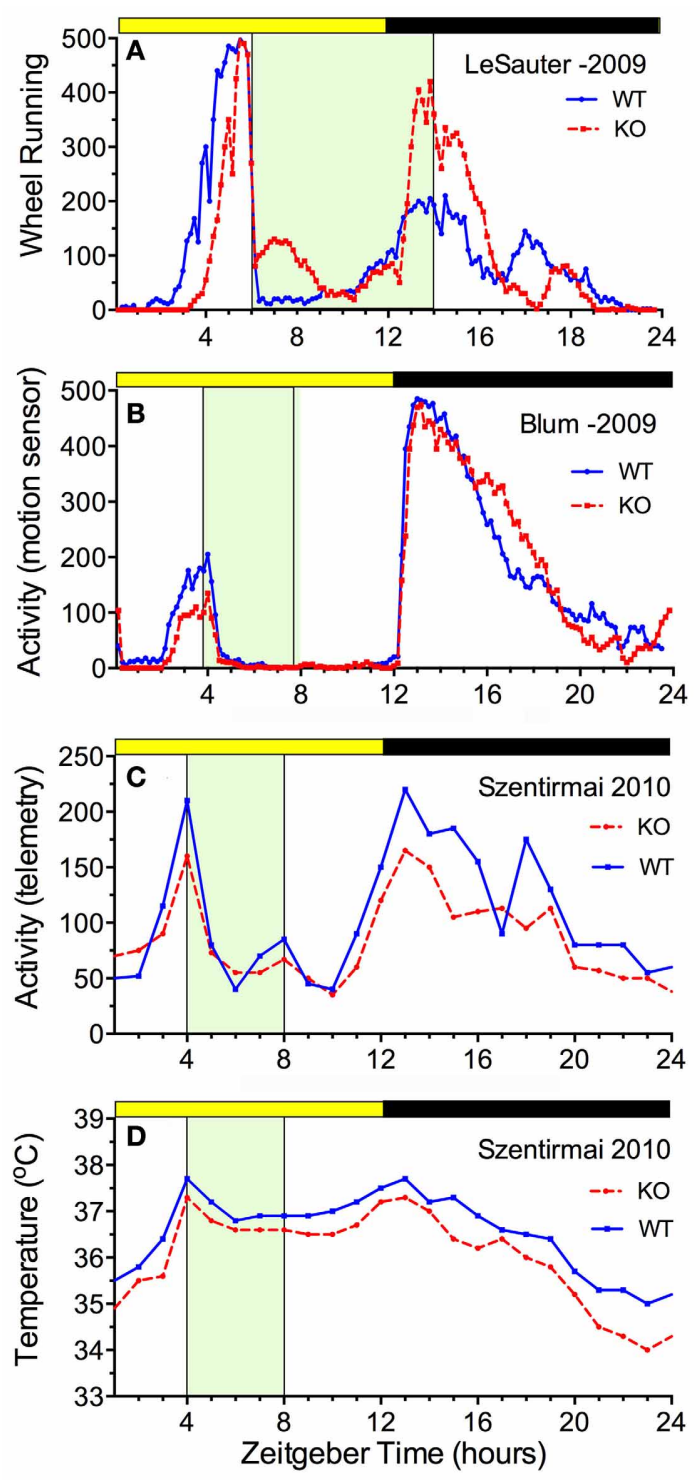

FIGURE 3 | Average waves illustrating the consequences of ghrelin receptor knockout $(A, B)$ and preproghrelin $K O(C, D)$ on food-entrained locomotor activity and body temperature in mice. Knockout groups are represented by the red dashed lines, WT by the solid blue lines. (A) The onset of wheel running activity is modestly delayed in ghrelin receptor knockout mice, but rises to the same level (LeSauter et al., 2009). (B) The onset of running is not delayed but rises to a lower level in ghrelin receptor knockout mice (Blum et al., 2009). (C) Locomotor activity measured by telemetry is slightly reduced at all time points in preproghrelin $\mathrm{KO}$ mice compared to WT mice, but increases equivalently prior to a 4-h daily meal in both groups (Szentirmai et al., 2010). (D) The same results were obtained for core body temperature measured by telemetry (Szentirmai et al., 2010).

et al., 2009) (Figure 3A), while in the other case, the peak level was reduced with little change in FAA duration (Blum et al., 2009) (Figure 3B).

In contrast to these 5 studies, there are two reports that ghrelin receptor knock out mice do not anticipate a daily meal. In one of these studies, food anticipation was quantified as the 
total number of beam breaks 2-h prior to a 4-h daily mealtime, during one baseline day and on day 14 of food restriction in a separate recording cage (Davis et al., 2011). Raw data $(24 \mathrm{~h}$ activity waveforms) were not provided, and without normalizing for total daily activity, comparing counts in a 2-h time bin does not provide information about the presence or absence of anticipation. Also, the mealtime, relative to the LD cycle was not specified. Consequently, the "evidence for absence" in this study is weak. The other study evaluated the effects of ghrelin receptor knockout on hyperactivity in mice induced by severe caloric restriction, in an "activity based anorexia" protocol (a 2-h daily meal provided at lights-off for 3-days; Verhagen et al., 2011a). WT mice exhibited daytime hyperactivity, which was absent in the $\mathrm{KO}$ mice. However, activity was maximal in the middle of the light period in both groups and decreased as the nocturnal mealtime approached, indicating that hyperactivity during the first 3 days of extreme caloric restriction in the WT mice was non-specific rather than food-anticipatory. When food is acutely restricted to a few hours/day, mice may exhibit hyperactivity for the first few days, which dissipates as the amount of food consumed during the mealtime increases, and a stable pattern of food anticipatory activity, peaking at expected mealtime time, emerges. If the caloric restriction is too severe, the hyperactivity does not dissipate, appetite is suppressed and metabolic collapse may ensue.

Collectively, the results of ghrelin knockout studies indicate that ghrelin secretion is not required for anticipation of a daily meal. If ghrelin does participate in circadian expression of food anticipatory activity under some experimental conditions, it is likely acting downstream from or in parallel with FEOs hypothesized to drive FAA, or it is redundant with other FEOs or with other signals that can entrain FEOs. The site of action of ghrelin may be both hypothalamic and mesocorticolimbic, given recent observations that ghrelin receptor $\mathrm{KO}$ mice exhibit lower levels of food-anticipatory cFos expression (a correlate of neuronal activity) in lateral hypothalamic orexin neurons, the VTA and the nucleus accumbens shell (Lamont et al., 2012). Whether ghrelin is responsible for controlling the phase of circadian oscillators in these areas, or in any peripheral tissues, has not yet been demonstrated.

\section{GHRELIN AND ANTICIPATION OF PALATABLE FOOD}

Food anticipation can also be observed in rats and mice without caloric restriction, by providing access to a palatable snack (e.g., chocolate) at a fixed time of day, with regular chow available ad-libitum (Mistlberger and Rusak, 1987; Mendoza et al., 2005; Hsu et al., 2010). Palatable feeding schedules are associated with induction of $c F o s$ prior to snack time in cortical and limbic structures involved in reward and motivation (n. accumbens core and shell, central nucleus of the amygdala, prefontal cortex). All of these areas express circadian rhythms of clock gene expression, and are innervated by dopaminergic projections from the VTA (Webb et al., 2009a). Neural activity in the VTA exhibits a daily rhythm, but clock gene expression in this area is constitutive rather than circadian, indicating that VTA rhythmicity is driven by inputs (Webb et al., 2009b; Moorman and Aston-Jones, 2010; Baltazar et al., 2013). A candidate rhythmic input is ghrelin, which increases the firing rate of VTA neurons that release DA in the VTA (Abizaid et al., 2006). This raises the possibility that ghrelin, by activating DA neurons in the VTA that innervate circadian oscillators in the limbic forebrain, might play a role as an entraining stimulus for daily rhythms of palatable food anticipation. If so, then ghrelin levels should rise in anticipation of a palatable meal, and ghrelin knockout or receptor antagonists should eliminate or attenuate palatable food anticipation.

Studies of plasma ghrelin levels in rats anticipating a daily palatable meal have yielded mixed results. One study reported that plasma ghrelin, sampled at the expected time of chocolate delivery ( $6 \mathrm{~h}$ after lights-on in LD 12:12), correlated positively with locomotor activity counts during the preceding $3 \mathrm{~h}$ (Merkestein et al., 2012). Ghrelin levels in these rats were intermediate between ghrelin levels in adlib fed rats and in rats restricted to a single daily meal at this time of day. A second study reported that plasma ghrelin was significantly increased 30 and $60 \mathrm{~min}$ prior to a daily $6 \mathrm{~h}$ meal consisting of regular chow or high fat chow, but was not elevated at 30,60, and 90 min time points prior to 2-h daily access to chocolate ( $5 \mathrm{~h}$ after lights-on), with regular chow available ad-libitum (Dailey et al., 2012). Rats in all 3 groups exhibited significant anticipatory activity, although the amount of anticipatory activity in rats receiving chocolate without food restriction was about half of that in the food restricted groups. These results indicate that elevated ghrelin is not necessary for the induction of anticipatory activity, but may promote its expression. An explanation for the different results in the two studies remains to be established, but could be related to the parameters of the feeding schedules (meal time and duration) or small differences in the blood sampling time points.

Anticipation of palatable foods without caloric restriction has not yet been assessed in ghrelin deficient mice. However, the ghrelin receptor antagonist JMV2959, administered i.c.v. 3-h prior to chocolate access, dose-dependently attenuated anticipatory activity by $40-60 \%$, while administration of acyl-ghrelin increased anticipatory activity by about $50 \%$ (Merkestein et al., 2012). These findings are consistent with a role for ghrelin as a modulatory factor in palatable meal anticipation.

\section{LEPTIN}

Leptin is an anorexigenic hormone released from adipose tissue in proportion to lipid stores (Zhang et al., 1994). Leptin acts in opposition to ghrelin at the ARC, inhibiting NPY/AgRP neurons and stimulating POMC/CART neurons, resulting in decreased food intake and increased metabolic rate (Kageyama et al., 2012). Serum leptin shows a daily rhythm in humans and mice, increasing during the waking/feeding period and decreasing during the sleeping/fasting period (Sinha et al., 1996; Ahima et al., 1998; Ahren, 2000; Shea et al., 2005). In humans, the rhythm is the net result of daily variations in food intake (leptin increases after feeding and decreases during fasting) and an endogenous clock (Shea et al., 2005). In mice, leptin synthesis and secretion are also subject to circadian regulation, at least in part by circadian oscillators intrinsic to adipocytes (Zvonic et al., 2006; Otway et al., 2009). However, expression of the daily rhythm of circulating leptin appears to be dependent on food intake. The rhythms of plasma leptin, and the adipocyte clock (Zvonic et al., 2006), are inverted 
if food is restricted to the middle of the light period, but the plasma leptin rhythm is abolished during total food deprivation (Ahima et al., 1998; Elimam and Marcus, 2002; Martinez-Merlos et al., 2004). Food anticipatory activity rhythms, as noted, persist robustly during several days of total food deprivation. This dissociation between circulating leptin levels and food anticipatory rhythms during food deprivation indicates that variations in plasma leptin do not drive the daily rhythm of food anticipatory behavior.

Consistent with this interpretation, leptin insensitive Zucker rats and leptin deficient ob:ob mice are obese and hypoactive when food is available ad-lib, but exhibit strong FAA when restricted to a single mid-day meal and the amount of FAA is increased relative to WT controls (Mistlberger and Marchant, 1999b; Ribeiro et al., 2011). Conversely, systemic administration of leptin reduces pre-meal activity in food-restricted rats/mice (Verhagen et al., 2011b). These results indicate that leptin, like ghrelin, plays a modulatory role in the expression of food anticipatory activity, consistent with its role in modulating food intake under free-feeding conditions.

\section{INSULIN AND GLUCAGON}

Homeostasis of plasma glucose is critically dependent on the pancreatic hormones insulin and glucagon. Food ingestion is the major stimulus for insulin secretion, but external stimuli that predict food intake also play an important role stimulating release (Woods et al., 1970). In the scheduled feeding paradigm, time of day (circadian phase) has been conceptualized as a conditioned stimulus for anticipatory insulin secretion (Woods et al., 1977). It is now established that the pancreas contains autonomous circadian oscillators that are reset by restricted daytime feeding, independently of the master clock in the SCN (Damiola et al., 2000). Insulin secreting beta cells are among those thought to contain an intrinsic circadian clock (Marcheva et al., 2010; Sadacca et al., 2011). Therefore, any increase in plasma insulin that occurs in rats at an expected daily mealtime (Wiley and Leveille, 1970; Woods et al., 1977; Drazen et al., 2006; Vahl et al., 2010) presumably reflects entrainment of local pancreatic oscillators, a process distinct from the central neural mechanisms that mediate stimulus-response conditioning of insulin release.

A food anticipatory increase in plasma insulin has not always been reported (e.g., Davidson and Stephan, 1999; Diaz-Munoz et al., 2000; Frecka and Mattes, 2008), This may be due to sampling time and resolution, as significant increases when reported appear to occur very close to mealtime (e.g., within $15 \mathrm{~min}$; Drazen et al., 2006; Vahl et al., 2010). This raises the possibility that preprandial insulin release in some studies is a conditioned response to noises made by research staff arriving in advance to deliver the daily meal (we have observed lever pressing for food conditioned to the sound of a door opening to enter an anteroom outside of an animal recording room, a few minutes prior to a daily mealtime; Peterson and Mistlberger, unpublished observations). Whatever the explanation for the different results across studies, the proximity of preprandial insulin release to mealtime rules out insulin as an initiator of food anticipatory activity, which typically begins $2-3 \mathrm{~h}$ before mealtime. It is also appears that prandial insulin release is not required for entrainment of oscillators driving FAA, because streptozotocine-induced diabetes in mice does not prevent induction of food anticipatory activity or resetting of circadian clocks in the liver, heart or kidney by restricted daytime feeding (Davidson et al., 2002; Oishi et al., 2004).

Glucagon, the other major pancreatic hormone, normally varies inversely with insulin. Two studies reported that plasma glucagon levels decrease in the hours preceding a scheduled daytime meal in rats (Davidson and Stephan, 1999; Diaz-Munoz et al., 2000). It has not been established that pancreatic alpha cells that produce glucagon possess an intrinsic circadian clock, and there is no evidence that glucagon participates in food anticipatory behavioral rhythms.

\section{GLUCAGON LIKE PEPTIDE 1}

Glucagon like peptide 1 (GLP-1) is synthesized in the periphery and in the brain. In the periphery GLP-1 is derived from preproglucagon synthesized in L cells of the intestine and alpha cells of the pancreas (Mojsov et al., 1990). In the CNS GLP-1 is produced in the nucleus of the solitary tract, the dorsal and central reticular nucleus, the PVN, DMH and to a lesser extent the ARC (Larsen et al., 1997). GLP-1 receptors are widely expressed in the CNS with large numbers in the ARC, PVN, and SON, and fewer in the lateral preoptic area, PVN, LH, bed nucleus of the stria terminalis and DMH (Shughrue et al., 1996). Most regions that express GLP-1 receptors are behind the $\mathrm{BBB}$, and whether peripheral GLP-1 has access to these receptors is under debate (Trapp and Hisadome, 2011). It is also not clear if post-prandial peripherally released GLP-1 signals for the release of central GLP-1.

Two studies have investigated the effects of restricted feeding schedules on GLP-1 secretion. In one study, rats were maintained on a 4-h daily meal beginning 5-h after lights-on for 14 days. Plasma GLP-1 was found to increase 4-fold over an interval from 75 to $60 \mathrm{~min}$ before the meal, and then decrease back to baseline levels $30 \mathrm{~min}$ before mealtime (Vahl et al., 2010). In a second study, rats anticipating a 6-h daily meal beginning 3$\mathrm{h}$ after lights-on also exhibited increased GLP-1 at 90 and $60 \mathrm{~min}$ before mealtime, and no difference at $30 \mathrm{~min}$ prior to the meal, by comparison with adlib fed rats. By contrast, a group of rats anticipating 2-h access to chocolate, without caloric restriction, showed no change in GLP-1 at 90, 60, or 30 min time points before feeding (Dailey et al., 2012). These results indicate that a premeal peak of GLP-1 is not necessary for anticipation of a daily palatable meal in the absence of caloric restriction. Whether the onset of GLP1 secretion prior to a single daily meal in calorically restricted rats correlates with the onset of anticipatory activity has not been assessed. Sustained increments of GLP-1 are clearly not required to produce the continuous food anticipatory activity typical of food-entrained rodents, but it is conceivable that an early GLP-1 spike is part of a cascade of responses that gate the onset of food anticipatory activity or entrain FEOs driving food anticipation.

\section{CENTRAL NEUROPEPTIDES MELANOCORTINS AND NEUROPEPTIDE $Y$}

Circulating ghrelin and leptin exert opposite effects on the expression of circadian food anticipatory activity, and may do this at least in part by differential effects on the central melanocortin 
system. The melanocortin system consists of separate populations of neurons in the arcuate nucleus that release ligands for melanocortin-3 (McR3) and melanocortin-4 (McR4) receptors. One population of arcuate neurons synthesizes POMC, a precursor for $\alpha, \beta$, and $\gamma$-melanocortin-stimulating hormones (MSH) which function as agonists at Mc3R and Mc4R receptors (Mountjoy, 2010). A second population of arcuate neurons corelease AgRP and NPY. AgRP acts as an inverse agonist at melanocortin receptors (Cone, 2005). Mc3R receptors are predominantly expressed in hypothalamic and limbic structures, with high levels in areas implicated in feeding and reward (VMH and VTA) (Roselli-Rehfuss et al., 1993), while Mc4R are more widely distributed within the brain.

The melanocortin system plays a critical role in the regulation of metabolism and feeding. $\alpha$-MSH potently inhibits feeding (Fan et al., 1997), whereas AgRP stimulates feeding (Small et al., 2001; Aponte et al., 2011; Krashes et al., 2011). Deletion of POMC and Mc3R and Mc4R receptors induces hyperphagia, obesity, hyperinsulinemia, insulin insensitivity and loss of response to leptin (Barsh and Schwartz, 2002; Sutton et al., 2006), whereas AgRP deletions induce anorexia and weight loss and eliminate the orexigenic response to ghrelin (Chen et al., 2005; Gropp et al., 2005; Luguet et al., 2005; Aponte et al., 2011). Given the effects of ghrelin and leptin deficiency on food anticipatory activity rhythms, a prediction is that melanocortin receptor deficient mice should also exhibit a food anticipation phenotype. $\mathrm{Mc} 4^{-/-}$mice exhibit normal FAA, but $\mathrm{Mc}^{-/-}$mice have been reported to exhibit significantly attenuated food anticipatory rhythms of wheel running activity and waking (Butler et al., 2000; Sutton et al., 2008). However, the data fall short of supporting a strong conclusion that Mc3 receptors are "required" for entrainment of behavioral rhythms to feeding schedules, given that anticipation was evident in $\mathrm{KO}$ mice when recordings were made for longer than a few days (Sutton et al., 2008). Also, normal levels of food anticipa-

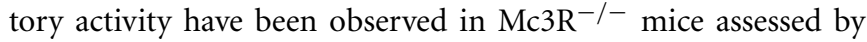
video based analyses (Steele, pers. commun.) and enhanced levels have been reported in mice lacking both Mc3 receptors and leptin assessed (Ribeiro et al., 2011). Whether differences in the amount of anticipatory activity observed in $\mathrm{Mc} 3 \mathrm{R}^{-/-}$mice studied in different labs is related to methodological differences (e.g., recording devices) or to the use of knockout mice obtained from different sources remains to be evaluated.

AgRP neurons co-release the potent orexigen NPY. Synthesis and release of NPY in the rat hypothalamus exhibits a daily rhythm with a peak prior to the nocturnal feeding period in adlib fed rats and prior to a schedule daily meal in food restricted rats (Akabashi et al., 1994; Xu et al., 1999; Yoshihara et al., 1996). Central administration of NPY induces behavioral and endocrine responses characteristic of rats anticipating a daily meal, including secretion of insulin and corticosterone and increased locomotor activity (Stanley and Leibowitz, 1984; Smialowska et al., 1994; Sainsbury et al., 1997). Despite this functional profile, NPY appears to be dispensable for induction of food anticipatory activity rhythms. NPY KO mice show reduced food anticipatory activity on day 7 of restricted daytime feeding but normal food anticipation by day 14 (Gunapala et al., 2011). Treatment of neonatal rats with monosodium glutamate severely reduces NPY immunoreactivity in the arcuate nucleus, but does not attenuate food anticipatory activity in rats (Mistlberger and Antle, 1999a). Radiofrequency lesions of the hypothalamic paraventricular nucleus, a hot spot for orexigenic effects of NPY, also do not impair food anticipatory activity in rats (Mistlberger and Rusak, 1988).

\section{OREXIN/HYPOCRETIN}

Orexin A and B (hypocretin 1 and 2) are derived from prepro-orexin synthesized exclusively in a population of neurons distributed within the dorsomedial, perifornical and lateral hypothalamic areas (Date et al., 1999). Orexin neurons project widely throughout the hypothalamus, thalamus, brain stem, and forebrain (Peyron et al., 1998). Orexins act via two G-protein coupled receptors. OX1R is selective for orexin A whereas OX2R binds both orexin A and B with similar affinity. When administered ICV to rats and mice, orexin A acutely stimulates feeding (Lubkin and Stricker-Krongrad, 1998; Sakurai et al., 1998), plasma corticosterone, wakefulness (Hagan et al., 1999), and locomotion (Nakamura et al., 2000). Orexin neurons are activated by a variety of stimuli, including hypoglycemia, caloric restriction, ghrelin administration and non-specific arousal (Sakurai et al., 1998; Cai et al., 1999; Yamanaka et al., 2003; Webb et al., 2008). Conversely, antagonism of ORX1R reduces food intake and body weight (Smart et al., 2002). Restricted feeding has been found to increase FOS staining in orexin neurons in the LHA in a manner similar to glucose-deprivation (Kurose et al., 2002) and in anticipation of a daily meal (Akiyama et al., 2004).

The association of orexin neuron activity with systemic and behavioral variables relevant to food seeking behavior, and the broad distribution of orexinergic efferents within the central nervous system, makes this population of cells an intriguing candidate to mediate the effects of restricted feeding schedules on food anticipatory behavior. The results of ablation studies indicates that orexin neurons do play a role, but not as a driving oscillators responsible for timing anticipatory behavior. An early study using ibotenic acid to ablate lateral hypothalamic neurons nonspecifically in rats reported that while total daily activity was reduced, food anticipatory activity was not eliminated (Mistlberger and Rusak, 1988). Similar results were obtained using an orexin2saporin toxin to ablate neurons expressing orexin2 receptors, which include neurons producing orexin (Mistlberger et al., 2003). A more selective genetic ablation of orexin neurons occurs developmentally in orexin/ataxin-3 mice. This is associated with behavioral state instability similar to narcolepsy, loss of the increase in consolidated wakefulness that occurs during acute food deprivation, and attenuation of food anticipatory activity (Hara et al., 2001b; Akiyama et al., 2004; Mieda et al., 2004). Orexin ligand knockout mice may also exhibit a reduction in food anticipatory activity compared to WT mice, but nonetheless exhibit a comparable peak of activity at the expected mealtime during a total food deprivation test (Kaur et al., 2008) (Figures 4D-F). Circadian timing of food anticipatory activity can thus be described as more accurate and thus 

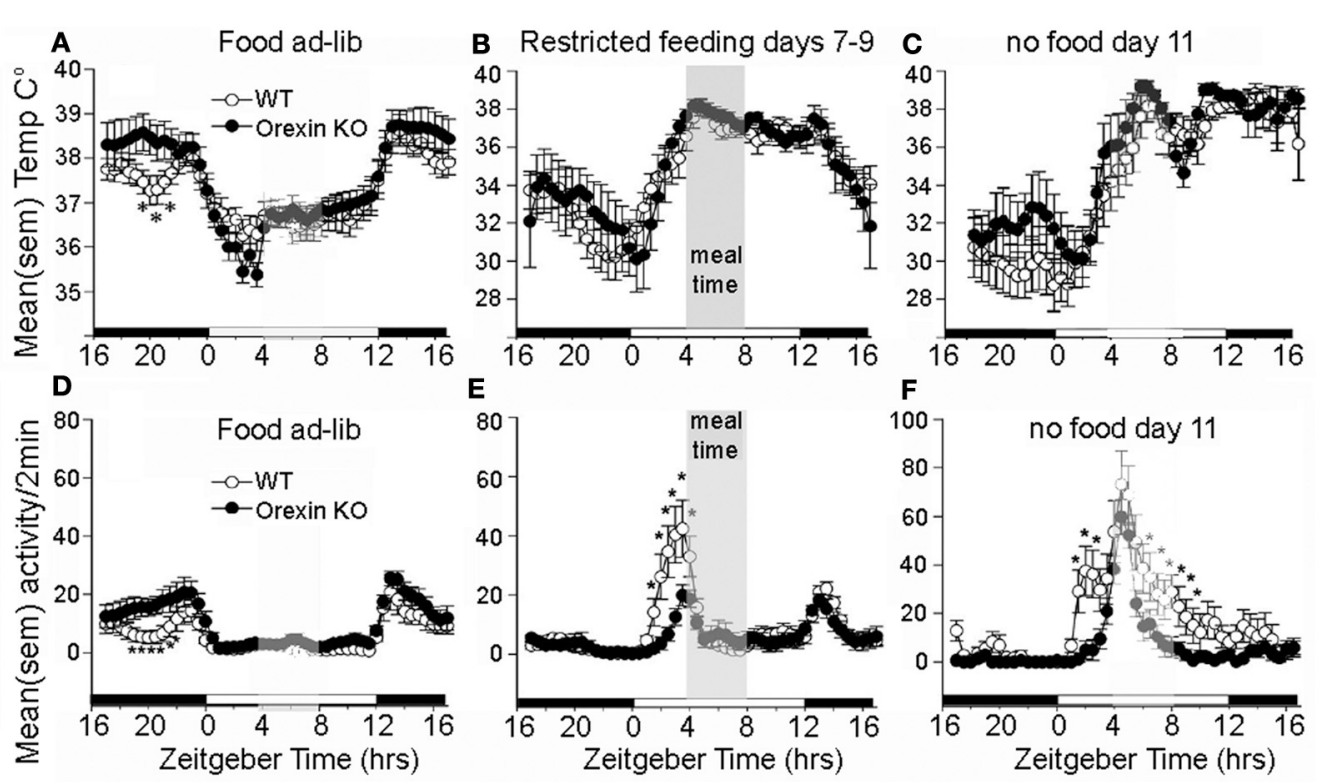

FIGURE 4 | Average waves illustrating daily rhythms of core body temperature (A-C) and locomotor activity (D-F) in WT mice (open circles) and orexin KO mice (closed circles). WT and KO mice show an equivalent anticipatory rise of body temperature prior to a 4-h daily meal (B) and this rhythm persists for at least 2 days of total food deprivation. (C) By contrast with WT mice, the KO mice exhibit attenuated anticipatory activity during days 7-9 of restricted feeding, but show an equivalent rise of activity at the expected mealtime during the second day without food, indicating that the timing mechanism for food anticipation is present despite the absence of orexin signaling. *significant $p<0.01$ between WT and KO. Adapted from Kaur et al. (2008). more efficient in these mice. The same study reported no deficit in the expression of the food anticipatory rise of body temperature (Figures $\mathbf{4 A - C}$ ), and a second study, using a video-based activity recording system detected no reduction in food anticipatory activity in orexin ligand KO mice (Gunapala et al., 2011). These results indicate that the effects of orexin deficiency on food anticipatory activity depend on the variable measured. Orexin neurons appear to play an important role regulating behavioral state stability and promoting wake consolidation during caloric restriction, but orexin and co-localized neuromodulators do not function as FEOs critical for timing food anticipatory activity or body temperature. Orexin neurons do interact with neural substrates mediating reward (Narita et al., 2006; Choi et al., 2010) and are activated in anticipation of reward (Harris et al., 2005), but a role in anticipation of palatable foods or other rewards provided on a circadian schedule has not yet been evaluated.

A portion of the orexinergic neuron population overlaps with the dorsomedial hypothalamus, which contains Mc3 receptors and neurons involved in regulating autonomic and neuroendocrine functions. Some neurons in this area exhibit daily rhythms of clock gene and immediate-early expression in rats and mice anticipating a daily meal (Gooley et al., 2006; Mieda et al., 2006; Verwey and Amir, 2009). Cell body specific lesions of this area may attenuate food anticipatory activity (Gooley et al., 2006; Acosta-Galvan et al., 2011; Landry et al., 2011), but complete removal of the area by radiofrequency ablation does not (Landry et al., 2006, 2007; Moriya et al., 2009). Also, clock gene oscillations in the dorsomedial hypothalamus are not induced in rats anticipating a daily palatable meal without caloric restriction, but are induced in rats maintained on a restricted feeding schedule with a random daily mealtime, which does not entrain anticipatory rhythms (AngelesCastellanos et al., 2008; Verwey et al., 2009). These results indicate that circadian oscillators in the dorsomedial hypothalamus are neither necessary nor sufficient for the induction of food anticipatory activity rhythms. Dorsomedial hypothalamic neurons are responsive to feeding related signals, and contain neurons projecting to the light-entrainable circadian clock in the SCN that may inhibit its output during the daily rest phase, thereby promoting the expression of food anticipatory activity (Acosta-Galvan et al., 2011; Landry et al., 2011).

\section{SUMMARY AND CONCLUSIONS}

Nocturnal animals normally work for food and eat at night. Scheduled feeding can markedly alter the timing of behavioral arousal and locomotor activity, resulting in concentrated periods of waking and food seeking behavior that anticipate expected meals, even if these occur during the usual rest phase of the circadian cycle. Similar changes have been reported in response to time-limited opportunities to obtain other rewards, including water, sex, and addictive drugs (Webb et al., 2009b). These behavioral changes are associated with shifting of circadian oscillators in the brain and in the periphery. However, the endocrine and neural substrates of entrainment of activity rhythms by food (and other rewards) remain to be clarified. Metabolic hormones and the hypothalamic circuits upon which they converge appear to 
play modulatory roles, increasing or decreasing the amplitude or duration of food anticipatory rhythms without being required for induction or persistence of these rhythms. These results, in combination with other lesion studies (Mistlberger, 1994; Davidson, 2009), suggest that FEOs critical for behavioral rhythms are either located outside of the hypothalamus, or are widely distributed and substantially redundant within the hypothalamus. Circadian oscillators reset by daily feeding schedules are also found in other brain regions, including mesocorticolimbic and dorsal striatal circuits that participate in reward processing and motivation for natural and drug reward (Verwey and Amir, 2009; Webb et al., 2009b). There is no direct evidence available yet that reward circuits are necessary or sufficient for entraining or driving food anticipatory circadian rhythms, but this remains a testable hypothesis.

Circadian clock adjustments induced by food intake are presumed to be adaptive, by coordinating rest-activity cycles with

\section{REFERENCES}

Abe, H., Kida, M., Tsuji, K., and Mano, T. (1989). Feeding cycles entrain circadian rhythms of locomotor activity in CS mice but not in C57BL/6J mice. Physiol. Behav. 45, 397-401. doi: 10.1016/0031-9384(89)90146-7

Abizaid, A., Liu, Z., Andrews, Z. B., Shanabrough, M., Borok, E., Elsworth, J. D., et al. (2006). Ghrelin modulates the activity and synaptic input organization of midbrain dopamine neurons while promoting appetite. J. Clin. Invest. 116, 3229-3239. doi: 10.1172/JCI29867

Acosta-Galvan, G., Yi, C. X., van der Vliet, J., Jhamandas, J. H., Panula, P., Angeles-Castellanos, M., et al. (2011). Interaction between hypothalamic dorsomedial nucleus and the suprachiasmatic nucleus determines intensity of food anticipatory behavior. Proc. Natl. Acad. Sci. U.S.A. 108, 5813-5818. doi: 10.1073/pnas.1015551108

Ahima, R. S., Prabakaran, D., and Flier, J. S. (1998). Postnatal leptin surge and regulation of circadian rhythm of leptin by feeding. J. Clin. Invest. 101, 1020-1027. doi: 10.1172/JCI1176

Ahren, B. (2000). Diurnal variation in circulating leptin is dependent on gender, food intake and circulating insulin in mice. Acta Physiol. Scand. 169, 325-331. doi: 10.1046/j.1365201x.2000.00746.x

Akabashi, A., Levin, N., Paez, X., Alexander, J. T., and Leibowitz, S. F. (1994). Hypothalamic neuropeptide $\mathrm{Y}$ and its gene expression: relation to light/dark cycle and circulating corticosterone. Mol. Cell. Neurosci. 5, 210-218. doi: 10.1006/mcne.19 94.1025
Akiyama, M., Yuasa, T., Hayasaka, N., Horikawa, K., Sakurai, T., and Shibata, S. (2004). Reduced food anticipatory activity in genetically orexin (hypocretin) neuron ablated mice. Eur. J. Neurosci. 20, 3054-3062. doi: 10.1111/j.14609568.2004.03749.x

Angeles-Castellanos, M., SalgadoDelgado, R., Rodríguez, K., Buijs, R. M., and Escobar, C. (2008). Expectancy for food or expectancy for chocolate reveals timing systems for metabolism and reward. Neuroscience 155, 297-307. doi: 10. 1016/j.neuroscience.2008.06.001

Aponte, Y., Atasoy, D., and Sternson, S. M. (2011). AGRP neurons are sufficient to orchestrate feeding behavior rapidly and without training. Nat. Neurosci. 14, 351-355. doi: 10.1038/ nn.2739

Arble, D. M., Ramsey, K. M., Bass, J., and Turek, F. W. (2010). Circadian disruption and metabolic disease: findings from animal models. Best Pract. Res. Clin. Endocrinol. Metab. 24, 785-800. doi: 10.1016/j.beem.2010.08.003

Balsalobre, A., Brown, S. A., Marcacci, L., Tronche, F., Kellendonk, C., Reichardt, H. M., et al. (2000). Resetting of circadian time in peripheral tissues by glucocorticoid signaling. Science 289, 2344-2347. doi: 10.1126/science.289.5488.2344

Baltazar, R. M., Coolen, L. M., and Webb, I. C. (2013). Diurnal rhythms in neural activation in the mesolimbic reward system: critical role of the medial prefrontal cortex. Eur. J. Neurosci. 38, 2319-2327. doi: 10.1111/ejn.12224

Barsh, G. S., and Schwartz, M. W. (2002). Genetic approaches to

food availability, and metabolic functions with food ingestion. However, the sensitivity of circadian oscillators to food or other rewards could be maladaptive in at least two ways. First, entrainment to powerful rewards (e.g., palatable food, addictive drugs) could induce daily temporal windows of vulnerability to excessive reward seeking behavior. Second, feeding stimulated at irregular mealtimes could result in disrupted timing of metabolic processes, with negative consequences for metabolic functioning and health (Arble et al., 2010; Golombek et al., 2013). To the extent that stress alters food intake, food sensitive circadian clocks may therefor represent a pathway from stress to disease. This suggests a research agenda exploring effects of stress on temporal parameters of food intake, and associated changes in phase relationships among circadian oscillators that control behavior and physiology. This idea remains to be evaluated experimentally, but would benefit from progress in specifying the neurobiological mechanisms that mediate the effects of food intake on circadian rhythms.

studying energy balance: perception and integration. Nat. Rev. Gene. 3, 589-600.

Blum, I. D., Patterson, Z., Khazall, R., Lamont, E. W., Sleeman, M. W., Horvath, T. L., et al. (2009). Reduced anticipatory locomotor responses to scheduled meals in ghrelin receptor deficient mice. Neuroscience 164, 351-359. doi: 10 1016/j.neuroscience.2009.08.009

Bodosi, B., Gardi, J., Hajdu, I., Szentirmai, E., Obal, F., and Krueger, J. M. (2004). Rhythms of ghrelin, lepton, and sleep in rats: effects of the normal diurnal cycle, restricted feeding, and sleep deprivation. Am. J. Physiol. Regul. Integr. Comp. Physiol. 287, R1071-R1079. doi: 10.1152/ ajpregu.00294.2004

Boulos, Z., Rosenwasser, A. M., and Terman, M. (1980). Feeding schedule and the circadian organization of behavior in the rat. Behav. Brain Res. 1, 39-65. doi: 10.1016/01664328(80)90045-5

Boulos, Z., and Terman, M. (1980), Food availability and daily biological rhythms. Neurosci. Biobehav. Rev. 4, 119-131. doi: 10.1016/01497634(80)90010-X

Butler, A. A., Kesterson, R. A., Khong, K., Cullen, M. J., Pelleymounter, M. A., Dekoning, J., et al. (2000). A unique metabolic syndrome causes obesity in the melanocortin 3 receptor deficient mouse. Endocrinology 141, 3518-3521. doi: 10.1210/en. 141.9 .3518

Cai, X. J., Widdowson, P. S., Harrold, J., Wilson, S., Buckingham, R. E., Arch, J. R., et al. (1999). Hypothalamic orexin expression: modulation by blood glucose and feeding. Diabetes
48, 2132-2137. doi: 10.2337/diabetes.48.11.2132

Challet, E. (2010). Interactions between light, mealtime and calorie restriction to control daily timing in mammals. J. Comp. Physiol. B 180 631-644. doi: 10.1007/s00360-0100451-4

Chen, X., Ge, Y. L., Jiang, Z. Y., Liu, C. Q., Depoortere, I., and Peeters, T. L. (2005). Effects of ghrelin on hypothalamic glucose responding neurons in rats. Brain Res. 1055, 131-136. doi: 10.1016/j. brainres.2005.06.080

Choi, D. L., Davis, J. F., Fitgerald, M. E., and Benoit, S. C. (2010). The role of orexin-A in food motivation, reward-based feeding behavioral and food-induced neuronal activation in rats. Neuroscience 167, 11-20. doi: 10.1016/j.neuroscience. 2010.02.002

Cone, R. D. (2005). Anatomy and regulation of the central melanocortin system. Nat. Neurosci. 8, 571-578. doi: $10.1038 / \mathrm{nn} 1455$

Cowley, M. A., Smith, R. G., Diano, S., Tschop, M., Pronchuk, N., Grove, K. L., et al. (2003). The distribution and mechanism of action of ghrelin in the CNS demonstrates a novel hypothalamic circuit regulating energy homeostasis. Neuron 37, 649-661.

Cummings, D. E., Purnell, J. Q., Frayo, R. S., Schmidova, K., Wisse, B. E., and Weigle, D. S. (2001). A preprandial rise in plasma ghrelin levels suggests a role in meal initiation in humans. Diabetes 50, 1714-1719. doi: 10.2337/diabetes.50.8.1714

Dailey, M. J., Stingl, K. C., and Morgan, T. H. (2012). Dissociation between preprandial gut peptide release 
and food anticipatory activity. Endocrinology 153, 132-142. doi: 10.1210/en.2011-1464

Damiola, F., Le Minh, N., Preitner, N., Kornmann, B., Fleury-Olela, F., and Schibler, U. (2000). Restricted feeding uncouples circadian oscillators in peripheral tissues from the central pacemaker in the suprachiasmatic nucleus. Genes Dev. 14, 2950-2961. doi: 10.1101/ gad. 183500

Date, Y., Ueta, Y., Yamashita, H., Yamaguchi, H., Maksukura, S., Kangawa, et al. (1999). Orexins, orexigenic hypothalamic peptides, interact with autonomic, neuroendocrine and neuroregulatory systems. Proc. Natl. Acad. Sci. U.S.A. 96, 748-753. doi: 10.1073/pnas.96. 2.748

Davidson, A. J., Poole, A. S., Yamazaki, S., and Menaker, M. (2003). Is the food-entrainable circadian oscillator in the digestive system. Genes Brain Behav. 2, 32-39. doi: 10.1034/ j.1601-183X.2003.00005.x

Davidson, A. J., and Stephan, F. K. (1999). Plasma glucagon, glucose, insulin, and motilin in rats anticipating daily meals. Physiol. Behav. 66, 309-315. doi: 10.1016/S00319384(98)00308-4

Davidson, A. J., Stokkan, K. A., Yamazaki, S., and Menaker, M. (2002). Food-anticipatory activity and liver per1-luc activity in diabetic transgenic rats. Physiol. Behav. 76, 21-26. doi: 10.1016/S0031-9384 (02)00680-7

Davidson, A. J. (2009). Lesion studies targeting food-anticipatory activity. Eur. J. Neurosci. 30, 1658-1664. doi: 10.1111/j.1460-9568.2009.06961.x

Davis, J. F., Choi, D. L., Clegg, D. J., and Benoit, S. C. (2011). Signaling through the ghrelin receptor modulates hippocampal function and meal anticipation in mice. Physiol. Behav. 103, 39-43. doi: 10.1016/j. physbeh.2010.10.017

Diaz-Munoz, M., Vazquez-Martinez, O., Aguilar-Roblero, R., and Escobar, C. (2000). Anticipatory changes in liver metabolism and entrainment of insulin, glucagon, and corticosterone in food-restricted rats. Am. J. Physiol. Regul. Intergr. Comp. Physiol. 279, R2048-R2056.

Dibner, C., Schibler, U., and Albrecht, U. (2010). The mammalian circadian timing system: organization and coordination of central and peripheral clocks. Annu. Rev. Physiol. 72, 517-549. doi: 10.1146/ annurev-physiol-021909-135821

Drazen, D. L., Vahl, T. P., D’Alessio, D. A., Seeley, R. J., and Woods, S. C.
(2006). Effects of a fixed meal pattern on ghrelin secrestion: evidence for a learned response independent of nutrient status. Endocrinology 147, 23-30. doi: 10.1210/en.20050973

Elimam, A., and Marcus, C. (2002). Meal timing, fasting and glucocorticoids interplay in serum leptin concentrations and diurnal profile. Eur. J. Endocrinol. 147, 181-188. doi: 10.1530/eje.0.1470181

Fan, W., Boston, B. A., Kesterson, R. A., Hruby, V. J., and Cone, R. D. (1997). Role of melanocortinergic neurons in feeding and the agouti obesity syndrome. Nature 385, 165-168. doi: $10.1038 / 385165 \mathrm{a} 0$

Feillet, C. A., Albrecht, U., and Challet, E. (2006). "Feeding time" for the brain: a matter of clocks. J. Physiol. Paris 100, 252-260. doi: 10.1016/j.jphysparis.2007.05.002

Feillet, C. A., Mendoza, J., Albrecht, U., Pévet, P., and Challet, E. (2008). Forebrain oscillators ticking with different clock hands. Mol. Cell. Neurosci. 37, 209-221. doi: 10.1016/j.mcn.2007.09.010

Frecka, J. M., and Mattes, R. D. (2008). Possible entrainment of ghrelin to habitual meal patterns in humans. Am. J. Physiol. Gastrointest. Liver Physiol. 294, G699-G707. doi: 10. 1152/ajpgi.00448.2007

Golombek, D. A., Casiraghi, L., Agostino, P. V., Paladino, N., Duhart, J., Plano, S. A., et al. (2013). The times are changing: effects of circadian desynchronization on physiology and disease. J. Physiol. Paris 107, 310-322. doi: 10.1016/j. jphysparis.2013.03.007

Gooley, J. J., Schomer, A., and Saper, C. B. (2006). The doromedial hypothalamic nucleus is critical for the expression of food-entrainable circadian rhythms. Proc. Natl. Acad. Sci. U.S.A. 143, 1413-1422. doi: 10.1038/nn1651

Gropp, E., Shanabrough, M., Borok, E., Xu, A. W., Janoschek, R. Buch, T., Plum, L., et al. (2005). Agouti-related peptide-expressing neurons are mandatory for feeding. Nat. Neurosci. 8, 1289-1291. doi: 10.1038/nn1548

Guan, X., Yu, H., Palyha, O., McKee, K. K., Feighner, S. D., Sirinathsinghi, D. J. S., Smith, R. G., et al. (1997). Distribution of mRNA encoding the growth hormone secretagogue receptor in brain and peripheral tissues. Mol. Brain Res. 48, 23-29. doi: 10.1016/S0169-328X(97)00071-5

Guilding, C., and Piggins, H. D. (2007). Challenging the omnipotence of the suprachiasmatic timekeeper: are circadian oscillators present throughout the mammalian brain. Eur. J. Neurosci. 25, 3915-3216. doi 10.1111/j.1460-9568.2007.05581.x

Gunapala, K. M., Gallardo, C. M., Hsu, C. T., and Steele, A. D. (2011) Single gene deletions of orexin, leptin, neuropeptide $y$, and ghrelin do not appreciably alter food anticipatory activity in mice. PLoS ONE 6:e18377. doi: 10.1371/journal.pone.0018377

Hagan, J. J., Leslie, R. A., Patel, S., Evans, M. L., Wattam, T. A. Homles, S., et al. (1999). Orexin A activates locus coeruleus cell firing and increases arousal in the rat. Proc. Natl. Acad. Sci. U.S.A. 96 10911-10916. doi: 10.1073/pnas.96. 19.10911

Hara, R., Wan, K., Wakamatsu, H., Aida, R., Moriya, T., Akiyama, M. et al. (2001a). Restricted feeding entrains liver clock without participation of the suprachiasmatic nucleus. Genes Cells 6, 269-278. doi: 10.1046/j.1365-2443.2001.00419.x

Hara, J., Beuckmann, C. T., Nambu, T., Willie, J. T., Chemelli, R. M., Sinton, C. M., et al. (2001b) Genetic ablation of orexin neurons in mice results in narcolepsy, hypophagia, and obesity. Neuron 30 345-354. doi: 10.1016/S0896-6273 (01)00293-8

Harris, G. C., Wimmer, M., and AstonJones, G. (2005). A role for lateral hypothalamic orexin neurons in reward seeking. Nature 437, 556-559. doi: 10.1038/nature04071

Honma, K., Honma, S., and Hiroshige, T. (1984a). Selective depression of prefeeding corticosterone peak in the rat by sodium pentobarbital injection. Neuroendocrinology 38, 232-236. doi: 10.1159/000 123896

Honma, K., Honma, S., and Hiroshige, T. (1984b). Feeding-associated corticosterone peak in rats under various feeding cycles. Am. J. Physiol. 246, R721-R726.

Hsu, C. T., Patton, D. F., Mistlberger, R. E., and Steele, A. D. (2010). Palatable meal anticipation in mice. PLoS ONE 5:e11802. doi 10.1371/journal.pone.0011802

Kageyama, H., Takenoya, F., Hirako, S., Wada, N., Kintaka, Y., Inoue, S., et al. (2012). Neuronal circuits involving neuropeptide $\mathrm{Y}$ in hypothalamic arcuate nucleusmediated feeding regulation. Neuropeptides 46, 285-289. doi: 10. 1016/j.npep.2012.09.007

Kaneko, M., Kaneko, K., Shinsako, J. and Dallman, M. (1981). Adrenal sensitivity to adrenocorticotropin varies diurnally. Endocrinology 109 70-75. doi: 10.1210/endo-109-1-70
Kaur, S., Thankachan, S., Begum, S., Blanco-Centurion, C., Sakurai, T., Yanagisawa, M., et al. (2008). Entrainment of temperature and activity rhythms to restricted feeding in orexin knock out mice. Brain Res. 1205, 47-54. doi: 10.1016/j.brainres.2008.02.026

Kirchner, H., Gutierrez, J. A., Solenberg, P. J., Pfluger, P. T., Czyzyk, T. A., Willency, J. A., et al. (2009). GOAT links dietary lipids with the endocrine control of energy balance. Nat. Med. 15, 741-745. doi: 10.1038/nm.1997

Kojima, M., Hosoda, H., Date, Y., Nakazato, M., Matsuo, H., and Kangawa, K. (1999). Ghrelin is a growth-hormone-releasing acylated peptide from stomach. Nature 402, 656-660. doi: 10.1038/45230

Krashes, M. J., Koda, S., Ye, C., Rogan, S. C., Adams, A. C., Cusher, D. S., et al. (2011). Rapid, reversible activation of AgRP neruons drives feeding behavior in mice. $J$. Clin. Invest. 121, 1424-1428. doi: 10.1172/JCI46229

Krieger, D. T. (1974). Food and water restriction shifts corticosterone, temperature, activity and brain amine periodicity. Endocrinology 95, 1195-1201. doi: 10.1210/endo-95-5-1195

Kurose, T., Ueta, Y., Yamamoto, Y., Serino, R., Ozaki, Y., Saito, J., et al. (2002). Effects of restricted feeding on the activity of hypothalamic orexin (OX)-A containing neurons and OX2 receptor mRNA level in the paraventricular nucleus of rats. Regul. Pept. 104, 145-151. doi: 10.1016/S0167-0115(01)00340-8

Lamont, E. W., Patterson, Z. Rodrigues, T., Vallejos, O., Blum, I. D., and Abizaid, A. (2012). Ghrelindeficient mice have fewer orexin cells and reduced cFOS expression in the mesolimbic dopamine pathway under a restricted feeding paradigm. Neuroscience 218, 12-19. doi: 10.1016/j.neuroscience.2012. 05.046

Landry, G. J., Kent, B. A., Patton, D. F., Jaholkowski, M., Marchant, E. G., and Mistlberger, R. E. (2011). Evidence for time-of-day dependent effect of neurotoxic dorsomedial hypothalamic lesions on food anticipatory circadian rhythms in rats. PLoS ONE 6:e24187. doi: 10.1371/journal. pone. 0024187

Landry, G. J., Simon, M., Webb, I. C., and Mistlberger, R. E. (2006). Persistence of a behavioral food anticipatory circadian rhythm following dorsomedial hypothalamic ablation in rats. Am. J. 
Physiol. 290, R1527-R1534. doi: 10.1152/ajpregu.00874.2005

Landry, G. J., Yamakawa, G. R., Webb, I. C., Mear, R. J., and Mistlberger, R. E. (2007). The dorsomedial hypothalamic nucleus is not necessary for the expression of circadian food-anticipatory activity in rats. J. Biol. Rhythms 22, 467-478. doi: 10.1177/0748730407307804

Larsen, P. J., Tang-Christensen, M., Hoist, J. J., and Orskov, C. (1997). Distribuition of glucagon-like peptide-1 and other preproglucagon-derived peptides in the rat hypothalamus and brainstem. Neuroscience 77, 257-270. doi: 10.1016/S0306-4522(96)00434-4

LeMinh, N., Damiola, F., Tronche, F., Schutz, G., and Schibler, U. (2001). Glucocorticoid hormones inhibit food-induced phase-shifting of peripheral circadian oscillators. $E M B O \quad$ J. 20, 7128-7136. doi: 10.1093/emboj/20.24.7128

LeSauter, J., Hoque, N., Weintraub, M., Pfaff, D., and Silver, R. (2009). Stomach ghrelin-secreting cells as food entrainable circadian clocks. Proc. Natl. Acad. Sci. U.S.A. 106, 13582-13587. doi: 10.1073/pnas.0906426106

Liu, J., Prudom, C. E., Nass, R., Pezzoli, S. S., Oliveri, M. C., Johnson, M. L., et al. (2008). Novel ghrelin assays provide evidence for independent regulation of ghrelin acylation and secretion in healthy young men. J. Clin. Endocrinol. Metab. 93, 1980-1987. doi: 10.1210/jc.20072235

Lubkin, M., and Stricker-Krongrad, A. (1998). Independent feeding and metabolic actions of orexins in mice. Biochem. Biophys. Res. Commun. 253, 241-245. doi: 10.1006/bbrc.1998.9750

Luguet, S., Perez, F. A., Hnasko, T. S., and Palmiter, R. D. (2005). NPY/AgRP neurons are essential for feeding in adult mice but can be ablated in neonates. Science 310, 683-685. doi: 10.1126/science. 1115524

Maniam, J., and Morris, M. J. (2012). The link between stress and feeding behaviour. Neuropharmacology 63, 97-110. doi: 10.1016/j.neuropharm. 2012.04.017

Marcheva, B., Ramsey, K. M., Buhr, E. D., Kobayashi, Y., Su, H., Ko, C. H., et al. (2010). Disruption of the clock components CLOCK and BMAL1 leads to hypoinsulinaemia and diabetes. Nature 466, 627-631. doi: 10.1038/nature09253

Martinez-Merlos, M. T., AngelesCastellanos, M., Diaz-Munoz, M., Aguilar-Roblero, R., Mendoza, J., and Escobar, C. (2004). Dissociation between adipose tissue signals, behavior and the food-entrained oscillator. J. Endocrinol. 181, 53-63. doi: $10.1677 /$ joe. 0.1810053

Mendoza, J., Angeles-Castellanos, M., and Escobar, C. (2005) Food entrainment by a palatable meal induces food-anticipatory activity and c-FOS expression in reward-related areas of the brain. Neuroscience 133, 293-303. doi: 10.1016/j.neuroscience.2005.01.064

Merkestein, M., Brans, M. A. D., Luijendijk, M. C., de Jong, J. W., Egecioglu, E., Dickson, S. L., et al. (2012). Ghrelin mediates anticipation to a palatable meal in rats. Obesity 20, 963-971. doi: 10.1038/oby. 2011.389

Mieda, M., Williams, S. C., Richardson, J. A., Tanaka, K., and Yanagisawa, M. (2006). The dorsomedial hypothalamic nucleus as a putative food-entrainable circadian pacemaker. Proc. Natl. Acad. Sci. U.S.A. 103, 12150-12155. doi: 10.1073/ pnas.0604189103

Mieda, M., Williams, S. C., Sinton, C. M., Richardson, J. A., Sakurai, T., and Yanagisawa, N. (2004). Orexin neurons function in an efferent pathway of a foodentrainable circadian oscillator in eliciting food-anticipatory activity and wakefulness. J. Neurosci. 24, 10493-10501. doi: 10.1523/ JNEUROSCI.3171-04.2004

Mistlberger, R. E. (1993). Effects of scheduled food and water access on circadian rhythms of hamsters in constant light, dark, and light:dark. Physiol. Behav. 53, 509-516. doi: 10.1016/0031-9384(93)90145-6

Mistlberger, R. E., Antle, M. C., Kilduff, T. S., and Jones, M. (2003). Food-and light-entrained circadian rhythms in rats with hypocretin2-saporin ablations of the lateral hypothalamus. Brain Res. 980, 161-168. doi: 10.1016/S0006-8993 (03)02755-0

Mistlberger, R. E., and Antle, M. C. (1999a). Neonatal monosodium glutamate alters circadian organization of feeding, food anticipatory activity and photic masking in the rat. Brain Res. 842, 73-83. doi: 10.1016/S0006-8993(99)01836-3

Mistlberger, R. E., and Marchant, E. G. (1999b). Enhanced food anticipatory rhythms in the genetically obese zucker rat. Physiol. Behav. 66, 329-335. doi: 10.1016/ S0031-9384(98)00311-4

Mistlberger, R. E., Kent, B. A., Chan, S., Patton, D. F., Weinberg, A., and Parfyonov, M. (2012). Circadian clocks for all meal times: anticipation of 2 daily meals in rats. PLOS ONE 7:e31772. doi: 10.1371/journal.pone.0031772

Mistlberger, R. E., and Rusak, B. (1987). Palatable daily meals entrain anticipatory rhythms in free feeding rats: dependence on meal size and nutrient content. Physiol. Behav. 41, 219-226. doi: 10.1016/00319384(87)90356-8

Mistlberger, R. E., and Rusak, B. (1988). Food anticipatory circadian rhythms in paraventricular and lateral hypothalamic lesioned rats. J. Biol. Rhythms 3, 277-292. doi: 10.1177/074873048800300306

Mistlberger, R. E. (1994). Circadian food-anticipatory activity: formal models and physiological mechanisms. Neurosci. Biobehav. Rev. 18, 171-195. doi: 10.1016/01497634(94)90023-X

Mistlberger, R. E. (2011). Neurobiology of food anticipatory circadian rhythms. Physiol. Behav. 104, 535-545. doi: 10.1016/j.physbeh. 2011.04.015

Mojsov, S., Kopczynski, M. G., and Habener, J. F. (1990). Both amidated and nonamidated forms of glucagon-like peptide I are synthesized in the rat intestine and pancreas. J. Biol. Chem. 265, 8001-8006.

Moorman, D. E., and Aston-Jones, G. (2010). Orexin/Hypocretin modulates response of ventral tegmental dopamine neurons to prefrontal activation: diurnal influences. J. Neurosci. 30, 15585-15599. doi: 10.1523/JNEUROSCI.2871-10.2010

Moriya, T., Aida, R., Kudo, T., Akiyama, M., Doi, M., Hayasaka, N., et al. (2009). The dorsomedial hypothalamic nucleus is not necessary for food-anticipatory circadian rhythms of behavior, temperature or clock gene expression in mice. Eur. J. Neurosci. 29, 1447-1460. doi: 10.1111/j.1460-9568.2009.06697.x

Mountjoy, K. G. (2010). Distribution and function of melanocortin receptors within the brain. $A d v$. Exp. Med. Biol. 681, 29-48. doi: 10.1007/978-1-4419-6354-3_3

Nakamura, T., Uramura, K., Nambu, T., Yada, T., Goto, K., Yanagisawa, M., et al. (2000). Orexin-induced hyperlocomotion and stereotypy are mediated by the dopaminergic system. Brain Res. 873, 181-187. doi: 10.1016/S0006-8993(00)02555-5

Nakazato, M., Murakami, N., Date, Y., Kojima, M., Matsuo, H., Kangawa, K., et al. (2001). A role for ghrelin in the central regulation of feeding. Nature 409, 194-198. doi: 10.1038/35051587

Narita, S. G., Nagumo, Y., Hashimoto, S., Narita, M., Khotib, J., Miyatake,
M., et al. (2006). Direct involvement of orexinergic systems in the activation of the mesolimbic dopamine pathway and related behaviors to morphine. J. Neurosci. 26, 398-405. doi: 10.1523/JNEUROSCI.276105.2006

Oishi, K., Kasamatsu, M., and Ishida, N. (2004). Gene- and tissue-specific alterations of circadian clock gene expression in streptozotocininduced diabetic mice under restricted feeding. Biochem. Biophys. Res. Commun. 317, 330-334. doi: 10.1016/j.bbrc.2004.03.055

Oster, H., Damerow, S., Kiessling, S., Jakubcakova, V., Abraham, D., Tian, J., et al. (2006). The circadian rhythm of glucocorticoids is regulated by a gating mechanism residing in the adrenal cortical clock. Cell Metab. 4, 163-173. doi: 10.1016/j.cmet.2006.07.002

Otway, D. T., Frost, G., and Johnston, J. D. (2009). Circadian rhythmicity in murine preadipocyte and adipocyte cells. Chronobiol. Int. 26, 1340-1354. doi: 10.3109/07420520903412368

Patterson, Z. R., and Abizaid, A. (2013). Stress induced obesity: lessons from rodent models of stress. Front Neurosci. 7:130. doi: 10.3389/fnins. 2013.00130

Patton, D., Marchant, E., Parfyonov, M., Smit, A., Opiol, H., Patterson, Z., et al. (2012). Multiple daily meals: effects on behavior, peripheral oscillators and associated hormones. Soc. Res. Biol. Rhythms Abstr. 13, 130.

Peyron, C., Tighe, D. K., van den Pol, A. N., de Lecea, L., Heller, H. C., Sutcliffe, J. G., et al. (1998). Neurons containing hypocretin (orexin) project to multiple neuronal systems. J. Neurosci. 18, 9996-10015.

Pezuk, P., Mohawk, J. A., Wang, L. A., and Menaker, M. (2012). Glucocorticoids as entraining signals for peripheral circadian oscillators. Endocrinology 153, 4775-4783. doi: 10.1210/en.2012 1486

Reddy, A. B., Maywood, E. S., Karp, N. A., King, V. M., Inoue, Y., Gonzales, F. J., et al. (2007). Glucocorticoid signaling synchronizes the liver circadian transcriptome. Hepatology 45, 1478-1488. doi: 10.1002/hep.21571

Ribeiro, A. C., Ceccarini, G., Dupre, C., Friedman, J. M., Pfaff, D. W., and Mark, A. L. (2011). Contrasting effects of leptin on food anticipatory and total locomotor activity. PLoS ONE 6:e23364. doi: 10.1371/journal.pone.0023364 
Roselli-Rehfuss, L., Mountjoy, K. G., Robbins, L. S., Mortrud, M. T., Low, M. J., Tatro, J. B., et al. (1993). Indentification of a receptor for gamma melanotropin and other proopiomelanocortin peptides in the hypothalamus and limbic system. Proc. Natl. Acad. Sci. U.S.A. 90, 8856-8860. doi: 10.1073/pnas.90.19.8856

Sadacca, L. A., Lamia, K. A., deLemos, A. S., Blum, B., and Weitz, C. J. (2011). An intrinsic circadian clock of the pancreas is required for normal insulin release and glucose homeostasis in mice. Diabetologica 54, 120-124. doi: 10.1007/s00125010-1920-8

Sainsbury, A., Rohner-Jeanrenaud, F., Cusin, I., Zakrzewska, K. E., Halban, P. A., Gaillard, R. C., et al. (1997). Chronic central neuropeptide $\mathrm{Y}$ infusion in normal rats: status of the hypothalamopituitary-adrenal axis, and vagal mediation of hyperinsulinaemia. Diabetologia 40, 1269-1277. doi: $10.1007 / \mathrm{s} 001250050820$

Sakurai, T., Amemiya, A., Ishii, M., Matsuzaki, I., Chemelli, R. M., Tanaka, H., et al. (1998). Orexins and orexin receptors: a family of hypothalamic neurpeptides and G-protein-coupled receptors that regulate feeding behavior. Cell 92, 573-585. doi: 10.1016/S0092-8674(00)80949-6

Segall, L. A., Verwy, M., and Amir, S. (2008). Timed restricted feeding restores the rhythms of expression of the clock protein, Period 2, in the oval nucleus of the bed nucleus of the stria terminalis and central nucleus of the amygdala in adrenalectomized rats. Neuroscience 157, 52-56. doi: 10.1016/j.neuroscience.2008.08.055

Shea, S. A., Hilton, M. F., Orlova, C., Ayers, R. T., and Mantzoros, C. S. (2005). Independent circadian and sleep/wake regulation of adipokines and glucose in humans. J. Clin. Endocrinol. Metab. 90, 2537-2544. doi: 10.1210/jc.20042232

Shughrue, P. J., Lane, M. V., and Merchenthaler, I. (1996). Glucagonlike peptide-1 receptor (GLP-1R) mRNA in the rat hypothalamus. Endocrinology 137. 5159-5162. doi: 10.1210/en.137.11.5159

Sinha, M. K., Ohannesian, J. P., Heiman, M. L., Kriauciunas, A., Stephans, T. W., Magosin, S., et al. (1996). Nocturnal rise in leptin in lean, obese, and non-indulin-dependent diabetes mellitus subjects. J. Clin. Invest. 97, 1344-1347. doi: 10.1172/JCI118551
Sinha, R., and Jastreboff, A. M. (2013). Stress as a common risk factor for obesity and addiction. Biol. Psychiatry 73, 827-835. doi: 10.1016/j.biopsych.2013.01.032

Small, C. J., Kim, M. S., Staley, S. A., Mitchell, J. R., Murphy, K., Morgan, D. G., et al. (2001). Effects of chronic central nervous system administration of agoutirelated protein in pair fed animals. Diabetes 50, 248-254. doi: 10.2337/diabetes.50.2.248

Smart, D., Haynes, A. C., and Williams, G. (2002). Orexins and the treatment of obesity. Eur. J. Pharmacol. 440, 199-212. doi: 10.1016/S00142999(02)01429-2

Smialowska, M., Lewinska, G., and Tokarski, K. (1994). The role of $\alpha-1$ adrenergic receptors in the stimulating effect of neuropeptide Y (NPY) on rat behavioural activity. Neuropeptides 26, 225-232. doi: 10.1016/01434179(94)90074-4

Stanley, B. G., and Leibowitz, S. F. (1984). Neuropeptide Y: stimulation of feeding and drinking by injection into the paraventricular nucleus. Life Sci. 35, 2635-2642. doi: 10.1016/0024-3205(84)90032-8

Stephan, F. K., Schwann, J. M., and Sisk, C. L. (1979). Anticipation of $24 \mathrm{hr}$ feeding schedules in rats with lesions of the suprachiasmatic nucleus. Behav. Neural Biol. 25, 346-363. doi: 10.1016/S01631047(79)90415-1

Stephan, F. K. (1989). Forced dissociation of activity entrained to $\mathrm{T}$ cycles of food access in rats with suprachiasmatic lesions. J. Biol. Rhythms 4, 467-479. doi: 10.1177/074873048900400406

Stephan, F. K. (2002). The "other" circadian system: food as a Zeitgeber. J. Biol. Rhythms 17, 284-292. doi: 10.1177/074873040201700402

Stokkan, K. A., Yamazaki, S., Tei, H., Sakaki, Y., and Menaker, M. (2001). Entrainment of the circadian clock in the liver by feeding. Science 291, 490-493. doi: 10.1126/science.291. 5503.490

Sujino, M., Furukawa, J., Koinuma, S. Fujioka, A., Nagano, M., Iigo, M., et al. (2012). Differential entrainment of peripheral clocks in the rat by glucocorticoid and feeding. Endocrinology 153, 2277-2286. doi: 10.1210/en.2011-1794

Sutton, G. M., Perez-Tilve, D., Nogueiras, R., Fang, J., Kim, J. K., Cone, R. D., et al. (2008). The melanocortin-3 receptor is required for entrainment to meal intake. J. Neurosci. 28, 12946-12955. doi: 10.1523/JNEUROSCI.3615-08.2008
Sutton, G. M., Trevaskis, J. L., Hulver, M. W., McMillan, R. P., Markward, N. J., Babin, M. J. et al. (2006). Diet-genotype interactions in the development of the obese, insulin-resistant phenotype of c57BL/6J mice lacking melanocortin-3 or-4 receptors. Endocrinology 147, 2183-2196. doi: 10.1210/en.2005-1209

Szentirmai, É., Kapas, L., Sun, Y., Smith, R. G., and Krueger, J. M. (2010). Restricted feeding-induced sleep, activity, and body temperature changes in normal and preproghrelin-deficient mice. Am. J. Physiol. Regul. Integr. Comp. Physiol. 298, R467-R477. doi: 10.1152/ ajpregu.00557.2009

Szentirmai, É. (2012). Central but not systemic administration of ghrelin induces wakefulness in mice. PLoS ONE 7:e41172. doi: 10.1371/journal.pone.0041172

Toshinai, K., Yamaguchi, H., Sun, Y., Smith, R. O., Yamanaka, A., Sakurai, T., et al. (2006). Des-acyl ghrelin induces food intake by a mechanism independent of the growth hormone secretagogue receptor. Endocrinology 147, 2306-2314. doi: 10.1210/en.2005-1357

Trapp, S., and Hisadome, K. (2011) Glugacon-like peptide 1 and the brain: central actions-central sources. Auto. Neurosci. 161, 14-19. doi: 10.1016/j.autneu.2010. 09.008

Vahl, T. P., Drazen, D. L., Seeley, R. J., D'Alessio, D. A., and Woods, S. C. (2010). Meal-anticipatory glucagon-like peptide-1 secretion in rats. Endocrinology 151, 569-575. doi: 10.1210/en.2009-1002

Verhagen, L. A., Luijendijk, M. C., Adan, R. A. (2011a). Leptin reduces hyperactivity in an animal model for anorexia nervosa via the ventral tegmental area Eur. Neuropsychopharmacol. 21, 274-281. doi: 10.1016/j.euroneuro. 2010.11.006

Verhagen, L. A., Egecioglu, E., Luijendijk, M. C., Hillebrand, J. J., Adan, R. A., and Dickson, S. L. (2011b). Acute and chronic suppression of the central ghrelin signaling system reveals a role in food anticipatory activity Eur. Neuropsychopharmacol. 21, 384-392. doi: 10.1016/j.euroneuro. 2010.06.005

Verwey, M., and Amir, S. (2009). Food-entrainable circadian oscillators in the brain. Eur. J. Neurosci. 30, 1650-1657. doi: 10.1111/j.14609568.2009.06960.x

Verwey, M., Lam, G. Y., and Amir, S. (2009). Circadian rhythms of
PERIOD1 expression in the dorsomedial hypothalamic nucleus in the absence of entrained foodanticipatory activity rhythms in rats. Eur. J. Neurosci. 29, 2217-2222. doi: $\quad 10.1111 / \mathrm{j} .1460-9568.2009$. 06766.x

Weaver, D. R. (1998). The suprachiasmatic nucleus: a 25-year retrospective. J. Biol. Rhythms 13, 100-112. doi: 10.1177/074873098128999952

Webb, I. C., Baltazar, R. M., Lehman, M. N., and Coolen, L. M. (2009a). Bidirectional interactions between the circadian and reward systems: is restricted food access a unique zeitgeber. Eur. J. Neurosci. 30, 1739-1748. doi: 10.1111/j.14609568.2009.06966.x

Webb, I. C., Baltazar, R. M., Wang, X., Pitchers, K. K., Coolen, L. C., and Lehman, M. N. (2009b). Diurnal variations in natural and drug reward, mesolimbic tyrosine hydroxylase, and clock gene expression in the male rat. J. Biol. Rhythms 24, 465-476. doi: 10.1177/ 0748730409346657

Webb, I. C., Patton, D. F., Hamson, D., and Mistlberger, R. E. (2008). Neural correlates of arousal-induced circadian clock resetting:Hypocretin/orexin and the intergeniculate leaflet. Eur. J. Neurosci. 27, 828-835. doi: 10.1111/j.1460-9568.2008.06074.x

Welsh, D. K., Takahashi, J. S., and Kay, S. A. (2010). Suprachiasmatic nucleus: cell automony and network properties. Ann. Rev. Physiol. 72, 551-577. doi: 10.1146/annurevphysiol-021909-135919

Wiley, J. H., and Leveille, G. A. (1970). Significance of insulin in the metabolic adaptation of rats to a meal ingestion. J. Nutr. 100, 1073-1080.

Woods, S. C., Hutton, R. A., and Makous, W. (1970). Conditioned insulin secretion in the albino rat. Proc. Soc. Exp. Biol. Med. 133, 964-968. doi: 10.3181/00379727133-34605

Woods, S. C., Vasselli, J. R., Kaestner, E., Szakmary, G. A., Milburn, P., and Vitiello, M. V. (1977). Conditioned insulin secretion and meal feeding in rats. J. Comp. Physiol. Psychol. 91, 128-133. doi: 10.1037/ h0077307

Xu, B., Kalra, P. S., Farmerie, W. G., and Kalra, S. P. (1999). Daily changes in hypothalamic gene expression of neuropeptide, Y, galanin, proopiomelanocortin, and adipocyte leptin gene expression and secretion: effects of food restriction. Endocrinology 140, 2868-2875. doi: 10.1210/en.140.6.2868 
Yamanaka, A., Beuckmann, C. T., Willie, J. T., Hara, J., Tsujino, N., Mieda, M., et al. (2003). Hypothalamic orexin neurons regulate arousal according to energy balance in mice. Neuron 38, 701-713. doi: 10.1016/S0896-6273 (03)00331-3

Yamazaki, S., Numano, R., Abe, M., Hida, A., Takahashi, R., Ueda, M., et al. (2000). Resetting central and peripheral circadian oscillators in transgenic rats. Science 288, 682-685. doi: 10.1126/science.288. 5466.682

Yoshihara, T., Honma, S., and Honma, K. (1996). Effects of restricted daily feeding on neuropeptide $Y$ release in the rat paraventricular nucleus. AJP Endocrinol. Metab. 270, E589-E595.

Zhang, Y., Proeenca, R., Maffe, M. Barone, M., Leopold, L., and Friedman, J. M. (1994). Positional cloning of the mouse obese gene and its human homologue. Nature 372 425-432. doi: 10.1038/ $372425 \mathrm{a} 0$

Zvonic, S., Ptitsyn, A. A., Conrad, S. A., Scott, L. K., Floyd, Z. E., Kilroy, G., et al. (2006). Characterization of peripheral circadian clocks in adipose tissues. Diabetes 55, 962-970. doi: $10.2337 /$ diabetes.55.04.06.db 05-0873
Conflict of Interest Statement: The authors declare that the research was conducted in the absence of any commercial or financia relationships that could be construed as a potential conflict of interest.

Received: 20 July 2013; accepted: 24 September 2013; published online: 14 October 2013.

Citation: Patton DF and Mistlberger RE (2013) Circadian adaptations to meal timing: neuroendocrine mechanisms. Front. Neurosci. 7:185. doi: 10.3389/ fnins.2013.00185
This article was submitted to Neuroendocrine Science, a section of the journal Frontiers in Neuroscience. Copyright (C) 2013 Patton and Mistlberger. This is an open-access article distributed under the terms of the Creative Commons Attribution License (CC BY). The use, distribution or reproduction in other forums is permitted, provided the original author(s) or licensor are credited and that the original publication in this journal is cited, in accordance with accepted academic practice. No use, distribution or reproduction is permitted which does not comply with these terms. 